\title{
A distribuição dos pães na Santa Ceia da Ciência
}

O primeiro número do ano representa, de certa forma, a expressão da tomada de decisões da equipe de editores de uma revista e a conseqüente instigação a atitudes por parte dos leitores e colaboradores para o volume a seguir.

Este fluxo de ações parte, a princípio, dos eventos que se passaram no ano anterior e que, em nosso caso em particular, foram de importância histórica para o amadurecimento da revista.

O advento Scielo foi, a nosso ver, de significado destacado. Em artigo recente na revista Nature (31/01/2002), Alonso e Juricic relatam sua avaliação de algumas revistas médicas inseridas no catálago do International Scientific Institute (ISI). Por este estudo, os 5 periódicos nacionais que constam desta listagem tiveram um salto de 130\% no seu fator de impacto (índice que aponta o número de citações de autores das revistas por artigos em revistas indexadas) após sua inserção no Scielo. Isto torna óbvia a nova visibilidade que podemos atingir com a nossa recente incorporação à biblioteca científica eletrônica on-line.

Por outro lado, esta vantagem trás consigo a obrigação de sanarmos deficiências que já existam e que possam vir a surgir, para mantermos o nosso status quo.

A possibilidade de recebermos, no trâmite da indexação, sugestões construtivas quanto à nossa estrutura editorial nos faz antever que a busca de modificações possa se intensificar.

Para obter uma maior homogeneidade, tanto da produção científica quanto da avaliação dos artigos, elaboramos um suplemento denominado "Critérios de elaboração e avaliação de trabalhos científicos". Nele procuramos sintetizar os princípios das normas de Vancouver, utilizadas pela grande maioria dos periódicos das Ciências da Saúde em todo o mundo e que deverá passar a ser nossa referência a partir do número 68(2), além de delinearmos algumas das premissas que consideramos básicas para a elaboração de um trabalho de cunho científico.

Procuramos com esta iniciativa facilitar a vida do pesquisador iniciante, muitas vezes distante dos principais centros da produção científica nacional. Afora isso, vimos no suplemento, a possibilidade de uniformizarmos o trabalho desenvolvido por nosso Corpo Editorial, de mais de 100 revisores, que pode a partir de uma referência metodológica comum, apresentar maior liberdade na expressão de suas opiniões científicas a cerca dos artigos recebidos.
Salientamos que o acolhimento do manual não é obrigatório e esperamos que a participação de nossos leitores possa aperfeiçoá-lo continuamente.

Uma das indagações oferecidas pelo Scielo no momento de nossa aceitação no sistema, foi relativa à distribuição dos autores segundo região e unidade federativa (UF). Já há algum tempo vínhamos identificando uma nítida predominância dos Estados do Sul e Sudeste no montante de artigos publicados na revista. Esta percepção se transformou em preocupação, declarada ao Corpo Editorial em nossa reunião anual de 1999. Na ocasião solicitamos um empenho redobrado dos docentes das Instituições de Ensino de todos os Estados no incentivo à produção científica em seus Serviços. Desde então temos monitorado a produção por UF. Nada mudou. A nossa produção científica tem se apresentado com tendência fortemente regional, com o Estado de São Paulo perfazendo mais de 3/4 de todos os artigos da RBORL no ano de 2001. Foram 93 (77\%) artigos dos 122 do volume 67. Este número não é muito diferente dos obtidos em levantamento feito pela FAPESP em 2001 que mostrou que São Paulo era responsável por $66,7 \%$ de todos os trabalhos publicados em periódicos de Ciência e Tecnologia nacionais.

Mesmo assim, preocupados em identificar se a nossa revista estava representando uma amostra realista da produção científica otorrinolaringológica nacional, procuramos saber junto aos indexadores brasileiros disponíveis, aonde se fazia ciência de interesse para nossa área.

Foram selecionadas as seguintes bases de dados para a pesquisa: plataforma LATTES de currículos; diretório de grupos de pesquisa do CNPq; banco de teses do CAPES e lista de serviços de Residência Médica em ORL credenciados pelo MEC.

Uma vez levantados os números absolutos de cada UF para o ano de 2000, definimos sua porcentagem em relação ao país e correlacionamos cada dado com a porcentagem de trabalhos publicados na RBORL/2001 de cada Estado.

Dentre todos os programas de pós-graduação em Saúde que pudessem ter interesse por temas de ORL, obtivemos um total de 54 teses com objeto marcantemente otorrinolaringológico. Foram 16 serviços pesquisados, sendo 5 em ORL. Do total de teses defendidas (54), 42 foram concluídas em SP (78\%). 
O levantamento junto à plataforma LATTES de currículos, atualizado até o mês de janeiro de 2001, mostrou um total de 417 entradas de autores com produção em temas ORL. Deste total, 52\% tinham suas atividades centradas em SP. Dentre os pesquisadores especialistas em ORL cadastrados na plataforma 61\% são de SP. Os grupos de pesquisa que atuam na área também foram averiguados e localizamos $58 \%$ dos grupos situados em SP. As vagas para a Residência Médica em ORL mostraram que 158 (60\%) das 264 vagas existentes estão no Estado de São Paulo.

A participação de todas UF que tiveram autores em artigos no ano de 2001, está apresentada na tabela 1. disponibilizados para o fomento à pesquisa no Brasil. Os dados são para o ano de 1995, mas acreditamos que possam ser tomados como um bom parâmetro para os dias atuais, visto que poucas modificações foram implementadas em política de Ciência e Tecnologia nestes 5 anos.

Pelas cifras obtidas, o total de recursos federais disponibilizados para SP em 1995 foi de 28,09\% do total investido pelo governo federal em pesquisa, totalizando um montante de US\$ 626,64 milhões. Já os recursos estaduais foram de US\$715,82 milhões. Os dois volumes somados representam pouco mais de 60\% do total de recursos despendidos pelo governo federal sozinho. Esta porcentagem

Tabela 1. Valores relativos da participação de cada unidade federativa em cada uma das variáveis estudadas.

\begin{tabular}{|c|c|c|c|c|c|c|}
\hline UF & $\begin{array}{c}\% \text { de Artigos } \\
\text { publicados vol. } 67\end{array}$ & $\begin{array}{l}\% \text { de pesquisadores } \\
\text { com tema em ORL }\end{array}$ & $\begin{array}{l}\% \text { de pesquisadores } \\
\text { otorrinolaringologistas }\end{array}$ & $\begin{array}{c}\% \text { de vagas para } \\
\text { Residência em ORL }\end{array}$ & $\begin{array}{c}\% \text { de grupos de } \\
\text { pesquisa em ORL }\end{array}$ & $\begin{array}{c}\% \text { de teses defendidas } \\
\text { com tema ORL }\end{array}$ \\
\hline $\mathrm{AM}$ & 0,8 & 0,7 & 1,2 & 0 & 1,3 & 0 \\
\hline BA & 0,8 & 2,7 & 2,4 & 3,8 & 1,3 & 0 \\
\hline DF & 0,8 & 0,7 & 0 & 3,4 & 0 & 0 \\
\hline ES & 0 & 0,5 & 1,2 & 0 & 0 & 0 \\
\hline GO & 0,8 & 0,2 & 0 & 0 & 1,3 & 0 \\
\hline PR & 1,7 & 1,8 & 2,4 & 5 & 3,8 & 1,9 \\
\hline RJ & 7,4 & 6 & 6 & 11 & 6,3 & 9,3 \\
\hline RS & 1,7 & 16 & 15 & 5,7 & 8,8 & 3,7 \\
\hline SC & 0,8 & 2,2 & 2,4 & 0 & 2,5 & 0 \\
\hline SP & 77 & 53 & 61 & 60 & 58 & 78 \\
\hline AM & 0,8 & 0,2 & 1,2 & 0 & 1,2 & 0 \\
\hline
\end{tabular}

A análise comparativa dos números obtidos mostra uma forte correlação (Pearson) entre todas as variáveis e a publicação de artigos na RBORL (tabela 2). Entretanto, alguns Estados destoaram dos números gerais, tendo uma participação relativa na revista aquém do esperado por sua representação nos outros índices. Acredito que esta seja uma ocorrência eventual que provavelmente tenha uma variação no tempo.

Tabela 2. Correlação existente entre cada variável e a publicação de artigos na RBORL.

\begin{tabular}{lc}
\hline correlação & valor de Pearson \\
\hline artigo/pesquisador com interesse ORL & 0,961156 \\
artigo/pesquisador especialista & 0,974048 \\
artigo/vaga de residência & 0,990939 \\
artigo/grupo de pesquisa & 0,991046 \\
artigo/tese & 0,996912 \\
\hline
\end{tabular}

Satisfeita nossa curiosidade quanto à representação de nossa revista junto à comunidade científica ORL. Nos apropriamos de alguns números da Fundação de Amparo à Pesquisa do Estado de São Paulo (FAPESP) quanto aos valores não é muito diferente das obtidas para a produção científica para a ORL. Percebemos que também aqui podemos estabelecer uma forte correlação entre recurso e publicação na revista da SBORL.

Os dados são incisivos. Não é só de boa vontade que se faz ciência em um país soberano. Os incentivos financeiros precisam atingir as diversas áreas de interesse. No caso da Otorrinolaringologia, é notável a disparidade de produção científica entre os Estados. Também é notável a perseverança de pesquisadores abnegados em atividade nas universidades de Estados menos abonados.

Manifestamos aqui nossa admiração por sua participação e incitamos que ela seja exemplo para outros que possam estar nas mesmas condições a manterem as luzes da inteligência sempre acessas não importando o momento e a situação encontrada.

Um grande ano a todos!

Henrique Olival Costa Editor Executivo 